\title{
Predicting right ventricular failure after left ventricular assist device implantation: Frank and Starling prevail again
}

\author{
James K. Kirklin, MD
}

\author{
From the Division of Cardiothoracic Surgery, Department of Surgery, University of Alabama at Birmingham, \\ Birmingham, Ala. \\ Disclosures: Author has nothing to disclose with regard to commercial support. \\ Received for publication Aug 27, 2018; accepted for publication Aug 27, 2018; available ahead of print Oct 12, \\ 2018. \\ Address for reprints: James K. Kirklin, MD, Surgery, University of Alabama in Birmingham, 739 Zeigler Build- \\ ing, UAB Station, Birmingham, AL 35294 (E-mail: jkirklin@uabmc.edu). \\ J Thorac Cardiovasc Surg 2019;157:1034-5 \\ $0022-5223 / \$ 36.00$ \\ Copyright (C) 2018 by The American Association for Thoracic Surgery \\ https://doi.org/10.1016/j.jtcvs.2018.08.066
}

The right ventricular condition is of great import to the advanced heart failure medical and surgical teams when mechanical circulatory support is considered. Although the right ventricle is nearly always involved with the heart failure process, the differences in outcomes are profound when biventricular support is required. The poor survival when a right ventricular assist device is needed (40\% survival at 12 months) is documented by Amsallem and colleagues $^{1}$ in this issue of the Journal. This finding is supported by national and international cohorts, in which survival with biventricular support is consistently less than $50 \%$ at 1 year. $^{2}$ By multivariable analysis, the need for a right ventricular assist device at the time of left ventricular assist device (LVAD) implantation is consistently the number one risk factor for early-phase mortality. ${ }^{3}$ There is therefore great interest in developing risk models that are predictive of severe persisting right heart failure after LVAD implantation. Unfortunately, no predictive model developed to date has been sufficiently useful to gain meaningful penetration into the clinical arena.

Amsallem and colleagues ${ }^{1}$ have provided an in-depth analysis of the value of metrics describing right ventricular load adaptability in predicting the need for right ventricular support after LVAD implantation. ${ }^{1}$ The combination of echocardiographic and invasive hemodynamic studies generated a plethora of potentially predictive variables. Through detailed depictions and multivariable analytics, Amsallem and colleagues ${ }^{1}$ conclude that equivalent or superior predictions can be derived from filling pressures and end-systolic volume coupled with the overall state of the patient in the heart failure syndrome (INTERMACS [Interagency Registry for Mechanically Assisted Circulatory Support] profile).

In one of their concluding paragraphs, Amsallem and colleagues ${ }^{1}$ refer to the "simple is better" aphorism in

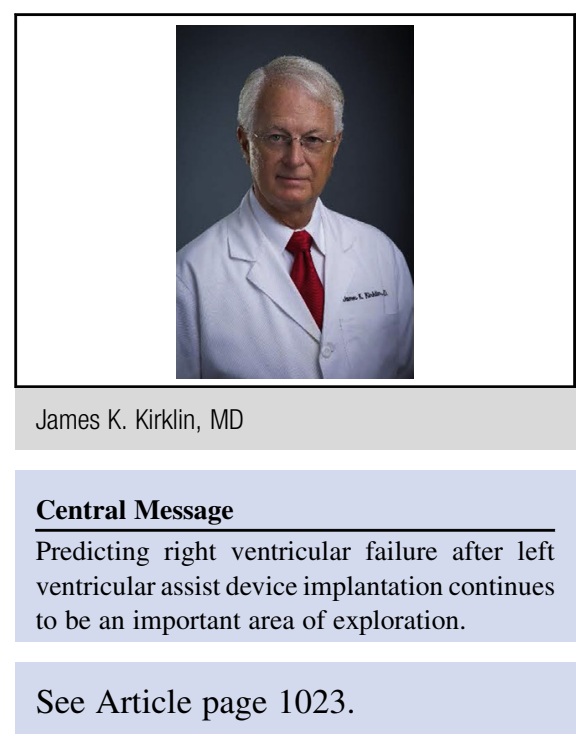

discussing the overriding importance of right atrial pressure in predicting the need for right ventricular support. Perhaps this elegant study has again reminded us of the fundamental derangements in the heart failure malady. Early elucidation of the mechanical characteristics of the heart by the famous physiologists Frank and Starling in the early 1900s paved the way for understanding the circulatory changes induced by the failing heart. The structural hallmark of the heart failure condition is cardiac remodeling, characterized by myocyte hypertrophy associated with chamber dilatation and alterations in the interstitial matrix. Still, the final common pathway for the debilitating and eventually fatal systemic manifestations of advanced heart failure is driven by progressive perturbation of the normal Frank-Starling mechanism, resulting in progressively higher atrial pressures (or end-diastolic volume) to achieve the same stroke volume, which eventually becomes inadequate as a state of low cardiac output ensues. It thus should not be surprising that, indeed, severely elevated right atrial pressure coupled with the sequelae of protracted and profound reduction in cardiac output (reflected by the more severe INTERMACS profiles) are particularly predictive of profound right ventricular failure after LVAD implantation.

Perhaps an important corollary from this excellent study is to seek application of these sophisticated metrics earlier in the heart failure trajectory. With the goal of 
identifying predictors of subsequent right heart failure before the advanced stages of clinical deterioration (with the accompanying marked elevation of right-sided pressures), pharmacologic interventions could be evaluated, in part, by trends in the load adaptability metrics. Researchers must continue the search for insights into the demarcation between recoverable and irreversible derangement of right ventricular function in advanced heart failure.

\section{References}

1. Amsallem M, Aymami M, Hiesinger W, Zeigler S, Moneghetti K, Marques M, et al. Right ventricular load adaptability metrics in patients undergoing left ventricular assist device implantation. J Thorac Cardiovasc Surg. 2019;157: 1023-33.

2. Kirklin JK, Xie R, Cowger J, de By TM, Nakatani T, Schueler S, et al. Second annual report from the ISHLT Mechanically Assisted Circulatory Support Registry. J Heart Lung Transplant. 2018;37:685-91.

3. Kirklin JK, Pagani FD, Kormos RL, Stevenson LW, Blume ED, Myers SL, et al. Eighth annual INTERMACS report: special focus on framing the impact of adverse events. J Heart Lung Transplant. 2017;36:1080-6. 